\title{
Characterization of the periplasmic cytochromes $c$ of Paracoccus denitrificans: identification of the electron acceptor for methanol dehydrogenase, and description of a novel cytochrome $c$ heterodimer
}

\author{
ANTHONY R. LONG and CHRISTOPHER ANTHONY* \\ Biochemistry Department, University of Southampton, Southampton SO9 5TU, UK
}

(Received 15 June 1990; revised 6 September 1990; accepted 27 September 1990)

\begin{abstract}
This paper describes periplasmic $c$-type cytochromes from two strains of Paracoccus denitrificans NCIB 8944 grown in heterotrophic or methylotrophic conditions. It is shown that the functions of two monomeric, monohaem cytochromes induced during growth on methanol have been wrongly designated in previous work. The CO-reactive cytochrome $c_{553}(30 \mathrm{kDa})$ is not the electron acceptor for methanol dehydrogenase; this is shown to be the role of the cytochrome $c_{552}(22 \mathrm{kDa})$. The monomeric $45 \mathrm{kDa}$ cytochrome induced in conditions of oxygen insufficiency is a dihaem $c$-type cytochrome and does not contain haem $b$ as previously assumed. In addition to these cytochromes, the Oxford strain of NCIB 8944 contains two cytochrome $c$ complexes. One of these (150 kDa), produced in relatively small amounts, consists of a non-haem protein plus four haemoproteins $(28,33,41$ and $47 \mathrm{kDa})$. The second complex is a novel dimeric multi-haem cytochrome $c(46 \mathrm{kDa})$ which constitutes about $25 \%$ of the periplasmic $c$-type cytochrome. It reacts with $\mathrm{CO}$ and has no methionine ligands. One subunit (16 kDa) has two low-spin haems; the larger subunit (30 kDa) has three haems which have low-spin characteristics in the oxidized state and are high-spin in the reduced state. The subunits were readily separated at $\mathrm{pH} 12$ and could be subsequently reconstituted into a complex indistinguishable from the original. The $30 \mathrm{kDa}$ subunit was denatured on prolonged exposure to high $\mathrm{pH}$, which also converted it to a low-spin cytochrome. No function could be designated for these novel $c$-type cytochrome complexes.
\end{abstract}

\section{Introduction}

Paracoccus denitrificans is an exceptionally versatile organism of considerable importance in the study of bioenergetics and of molecular biology of bioenergetic systems. Besides its atypical growth as an aerobic heterotroph, it can also grow in aerobic or anaerobic conditions as an autotroph with hydrogen plus carbon dioxide or as a methylotroph with methanol as sole source of carbon and energy. Of particular interest in this context is its ability to synthesize a variety of electrontransport mediators, the regulation of synthesis of these being mediated by the growth conditions. For example, at least four different periplasmic $c$-type cytochromes have been described, two of which have been implicated in methanol oxidation because their synthesis is induced during methylotrophic growth. There is some confusion in the literature over the functions of these cytochromes, however, and with the developing interest in the molecular biology of methanol oxidation and electron transport systems in $P$. denitrificans it is important to

Abbreviation: $\mathrm{MDH}$, methanol dehydrogenase. clarify their roles (see Ferguson, 1988; Harms et al., 1987; Page \& Ferguson, 1989, 1990; Raitio et al., 1990; van Spanning et al., 1990; de Vries 1986; de Vries et al., 1990).

The first evidence relating to the role of $c$-type cytochromes in methanol oxidation in $P$. denitrificans was the description of a CO-reactive cytochrome $c$ that was induced during growth on methanol; this was assumed to be involved specifically in methanol oxidation and was called cytochrome $c_{\mathrm{CO}}$ (van Verseveld \& Stouthamer, 1978). This was followed by the important demonstration by Alefounder \& Ferguson (1981) that methanol dehydrogenase (MDH) and the soluble $c$-type cytochromes are located exclusively in the periplasmic fraction of $P$. denitrificans; this has been very important in the development of methods of study of the $c$-type cytochromes in this organism. It was then shown that $P$. denitrificans is similar to other methylotrophs in having at least two soluble $c$-type cytochromes, only one of which is able to react with MDH (Beardmore-Gray et al., 1983). In $P$. denitrificans the soluble $c$-type cytochromes are acidic; in this respect this organism differs from other methylotrophs, in which the two cytochromes 
present during growth on methanol usually have markedly different isoelectric points. In other methylotrophs the acidic cytochrome is the specific electron acceptor for $\mathrm{MDH}$ and is called cytochrome $c_{\mathrm{L}}$ (Anthony, 1986; Nunn \& Anthony, 1988). The more basic cytochrome is usually called cytochrome $c_{\mathrm{H}}$ and is equivalent in structure and function to other typical class I $c$-type cytochromes such as the Paracoccus cytochrome $c_{550}$.

Three cytochromes $c$ (all acidic) were subsequently purified from the periplasm of $P$. denitrificans and characterized (Husain \& Davidson, 1986; Gray et al., 1986; Davidson \& Kumar, 1989). One was the wellknown cytochrome $c_{550}(15 \mathrm{kDa})$ and the other two were induced during growth on methanol. These were designated cytochrome $c_{551 \mathrm{i}}(22 \mathrm{kDa})$ and cytochrome $c_{553 \mathrm{i}}(30 \mathrm{kDa})$, which was the only one that reacted with $\mathrm{CO}$. It was concluded by these authors that cytochrome $c_{551}$ functions as the electron acceptor for the blue copper protein amicyanin, which is the specific electron acceptor for methylamine dehydrogenase during growth on methylamine. Although no experiments were described using $\mathrm{MDH}$, it was proposed that the $\mathrm{CO}$ binding cytochrome $c_{553 \mathrm{i}}$ is the electron acceptor for MDH (Davidson \& Kumar, 1989).

Bosma et al. (1987 $a, b)$ subsequently confirmed the presence of these three cytochromes in the periplasm of $P$. denitrificans. They suggested, however, that the $22 \mathrm{kDa}$ cytochrome $c_{552}$ (cytochrome $c_{551 i}$ of Husain \& Davidson, 1986) is not restricted to growth on $\mathrm{C}_{1}$ compounds but is the electron donor to cytochrome $a a_{3}$. They also reported a new dihaem cytochrome that was induced only under conditions of oxygen limitation (45 kDa; absorption maxima 551, $555 \mathrm{~nm}$ ). On the basis of absorption spectra, this was assumed to have one haem $c$ plus one haem $b$ (protohaem) per molecule.

In summary, it is generally agreed that there is a constitutive cytochrome $c_{\varsigma_{50}}$ (about $15 \mathrm{kDa}$ ) in $P$. denitrificans and that there are two soluble $c$-type cytochromes induced during growth on methanol. One of these, cytochrome $c_{553 i}$ (the $30 \mathrm{kDa}$ cytochrome also called cytochrome $c_{\mathrm{CO}}$ ) is generally assumed to be the electron acceptor for MDH (see also Ferguson, 1988; de Vries, 1986), and it has been suggested that the $22 \mathrm{kDa}$ cytochrome (cytochrome $c_{551 \mathrm{i}}$ ) functions as an electron acceptor in methylamine oxidation or as an electron donor to the oxidase

In the present paper it is demonstrated that cytochrome $c_{553}$ (or cytochrome $c_{\mathrm{CO}}$ ) is not the MDH electron acceptor and that the only electron acceptor for MDH is the $22 \mathrm{kDa}$ cytochrome (cytochrome $c_{551 \mathrm{i}}$ or $c_{552}$ ). It is also shown that the dihaem cytochrome $c(45 \mathrm{kDa})$ contains only haem $c$ and no haem $b$. Finally it is reported that one commonly used strain of $P$. denitrificans contains a remarkable cytochrome $c$ heterodimer with an unusual spin state which has not been previously described.

\section{Methods}

Bacterial strains and growth conditions. Paracoccus denitrificans NCIB 8944 was obtained from Dr S. J. Ferguson, Biochemistry Department, University of Oxford, UK, and from the NCIB, Torry Research Station, Aberdeen, UK. When these strains were found to differ in their cytochrome complements, the one from the University of Oxford was designated the Oxford strain. Both strains were maintained on $0.2 \%$ succinate agar slopes, prepared by addition of $1.5 \%(\mathrm{w} / \mathrm{v})$ bactoagar to the growth medium of Kornberg \& Morris (1965). P. denitrificans was grown at $30^{\circ} \mathrm{C}$ in batch culture in 1-litre volumes in 2litre conical flasks on an orbital shaker (120 r.p.m.) in the medium of Kornberg \& Morris (1965), containing either $0.35 \%$ (w/v) sodium succinate or $0.5 \%(\mathrm{w} / \mathrm{v})$ methanol. Oxygen-deficient bacteria were grown in the same way but the rate of shaking was diminished (to 40 r.p.m.) when the $\mathrm{OD}_{650}$ had reached about $1 \cdot 0$. Cultures were harvested when the $\mathrm{OD}_{650}(10 \mathrm{~mm}$ light path) was between 1.5 and 1.7 . Bacteria were harvested by centrifugation for $30 \mathrm{~min}$ at $4000 \mathrm{~g}$ at $4{ }^{\circ} \mathrm{C}$.

Preparation of periplasmic fractions. The method was based on that first described by Alefounder \& Ferguson (1981). The bacteria from 4 litres of culture were washed in 1 litre of ice-cold 10 mM-HEPES buffer (pH 7.3) containing $150 \mathrm{~mm}-\mathrm{NaCl}$. After centrifugation they were suspended in $200 \mathrm{ml} 200 \mathrm{~mm}$-HEPES buffer ( $\mathrm{pH} \mathrm{7.3)}$ containing $500 \mathrm{~mm}$-sucrose, $0.5 \mathrm{~mm}$ disodium EDT A and $25 \mathrm{~mm}$-methanol at room temperature. Lysozyme ( $200 \mathrm{mg}$ ), dissolved in $3 \mathrm{ml}$ cold distilled water, was added, followed by $200 \mathrm{ml}$ cold $25 \mathrm{~mm}$-methanol. After incubation at $30^{\circ} \mathrm{C}$ for $40 \mathrm{~min}$ with gentle swirling, the suspension was chilled on ice-water for $5 \mathrm{~min}$ and the spheroplasts harvested by centrifugation at $5000 \mathrm{~g}$ for $20 \mathrm{~min}$ at $4{ }^{\circ} \mathrm{C}$. The supernatant periplasmic fraction was decanted and protease inhibitors were added. These were benzamidine. $\mathrm{HCl}$ (final concentration $5 \mathrm{~mm}$ ) and phenylmethylsulphonyl fluoride $(0.5 \mathrm{~mm})$. The spheroplasts were then suspended in $100 \mathrm{ml}$ $20 \mathrm{~mm}$-HEPES buffer ( $\mathrm{pH} 7.3$ ) to lyse them, and a few grains of DNAase I added. Cell debris was removed by centrifugation $(5000 \mathrm{~g}$ for $15 \mathrm{~min}$ ) and the membrane fraction removed by ultracentrifugation at $300000 \mathrm{~g}$ for $1.5 \mathrm{~h}$.

Measurement of protein. Protein was measured by the method of Bradford (1976), with bovine serum albumin as standard. With the pure cytochromes, the protein concentrations determined by this method were almost identical to those obtained by using the bicinchoninic acid method adapted for use on microtitre plates as described by Smith et al. (1988) and the Lowry method.

Measurement of cytochrome reduction by $M D H$, and production and utilization of formaldehyde. The method used was that of BeardmoreGray et al. (1983), except for determination of kinetic constants for cytochrome $c_{\mathrm{L}}$, when the more rapid assay of Day \& Anthony (1990) was used.

Polyacrylamide gel electrophoresis of proteins and their staining. SDSPAGE was done at $\mathrm{pH} 8.8$ on linear gradient gels $(7.5-15 \%$, w/v) by the method of Lambin (1976) in the buffer system of Laemmli (1970). Staining of gels for haemoproteins was performed by the method of Thomas et al. (1976), and protein was stained with Coomassie Brilliant Blue R-250 as described by Weber \& Osborn (1975). Non-denaturing gels, run for confirmation of dimer reconstitution, were done in the same system but omitting SDS

Measurement of absorption spectra, cytochrome concentration, haem content and reaction with $C O$. All spectra were recorded using a Shimadzu UV-3000 spectrophotometer. Samples were reduced with a 
few grains of sodium dithionite or oxidized with a few grains of ammonium persulphate. Unless otherwise stated, spectra were run at $100 \mathrm{~nm} \mathrm{~min}-1$, with a spectral bandwidth of $1 \mathrm{~nm}$ and a light path of $10 \mathrm{~mm}$. Spectra were recorded at $77 \mathrm{~K}$ using the low-temperature attachment of the spectrophotometer using a $2 \mathrm{~mm}$ light path and $0.5 \mathrm{~nm}$ bandwidth.

The concentration of cytochrome $c$ was measured using absorption coefficients determined with the purified cytochromes; these are recorded in Results.

The haem content was determined by the pyridine haemochrome method of Fuhrhop \& Smith (1975).

For determination of reaction with carbon monoxide, $\mathrm{CO}$ was slowly passed through the cytochrome solution in a sealed cuvette for up to $10 \mathrm{~min}$. (Reduced $+\mathrm{Co}$ )-minus-reduced difference spectra were recorded immediately and up to $20 \mathrm{~min}$ after reaction. The extent of reaction with $\mathrm{CO}$ was estimated using the absorption coefficient of $55 \mathrm{~mm}^{-1} \mathrm{~cm}^{-1}$ (Wood, 1984) for the Soret peak to trough value.

Measurement of midpoint redox potentials. Procedures were essentially those of Dutton (1978) using the Shimadzu UV-3000 spectrophotometer in dual-wavelength mode as described previously (Day et al., 1990). The concentration of cytochrome was $1.7 \mu \mathrm{M}$.

Estimation of molecular masses by gel filtration on Superose-12 and Sephadex G-75. The Pharmacia Superose- 12 column (24 ml) was used after equilibration in $20 \mathrm{mM}$-HEPES buffer $(\mathrm{pH} 7.5)$ at a flow rate of $0.2 \mathrm{ml} \mathrm{min}-1$ and calibrated with the following proteins: apoferritin (443 kDa), $\beta$-amylase $(200 \mathrm{kDa})$, alcohol dehydrogenase $(150 \mathrm{kDa})$, ovalbumin $(45 \mathrm{kDa})$ and equine cytochrome $c(12.5 \mathrm{kDa})$. The same G-75 column was used as in the cytochrome purification work. It was calibrated with bovine serum albumin $(68 \mathrm{kDa})$, ovalbumin $(45 \mathrm{kDa})$, $\alpha$-chymotrypsinogen $(25.7 \mathrm{kDa})$ and equine cytochrome $c(12.5 \mathrm{kDa})$.

Estimation of the molecular masses of the cytochromes by $7.5-15 \%$ $S D S-P A G E$. The gradient gels were calibrated with standards obtained from Sigma (Sigma VII): bovine serum albumin ( $66 \mathrm{kDa}$ ), ovalbumin (45 kDa), carbonic anhydrase (29 kDa), trypsinogen (24 kDa), trypsin inhibitor $(20.1 \mathrm{kDa})$, cytochrome $c_{550}$ (Paracoccus) $(15.4 \mathrm{kDa})$ and $\alpha$-lactalbumin (14.2 kDa).

Western blotting. This was done exactly as described by Day et al. (1990), using antibody to the cytochrome $c_{550}$ of $P$. denitrificans kindly provided by $\mathrm{Dr}$ M. D. Page of Oxford University Biochemistry Department.

Purification of $M D H$. MDH was purified from the periplasmic fraction. It was assayed as previously described (Anthony \& Zatman, 1967). It was eluted from the same DEAE-Sepharose column as was used for cytochrome purification at $300 \mathrm{~mm}-\mathrm{NaCl}$. The pooled active fractions were concentrated to $10 \mathrm{ml}$ over an Amicon XM-50 membrane and applied to a gel filtration column of Sephacryl S-200 $(85 \times 3.5 \mathrm{~cm})$ equilibrated in $20 \mathrm{mM}-\mathrm{HEPES}$ buffer $(\mathrm{pH} 7.5)$ containing $200 \mathrm{~mm}-\mathrm{NaCl}$ and $25 \mathrm{~mm}$-methanol at $4{ }^{\circ} \mathrm{C}$. The purification was completed by anion-exchange chromatography on a column of QSepharose $(10 \times 2.5 \mathrm{~cm})$ equilibrated in $20 \mathrm{mM}$-HEPES buffer $(\mathrm{pH} 7.5)$ containing $25 \mathrm{~mm}$-methanol. After washing the column with the same buffer containing $300 \mathrm{mM}-\mathrm{NaCl}$ the $\mathrm{MDH}$ was eluted with $400 \mathrm{~mm}$ $\mathrm{NaCl}$. Salt was removed by concentration over an Amicon XM-50 membrane followed by gel filtration on a PD-10 column equilibrated with 20 mM-HEPES (pH 7.5) buffer containing 25 mm-methanol. The preparation was homogeneous on SDS-PAGE. It was stored at $-17^{\circ} \mathrm{C}$

Purification of the c-type cytochromes from the periplasm of $P$. denitrificans. Periplasmic protein [5.5 litres $(2.2 \mathrm{~g}$ protein)], in $20 \mathrm{~mm}$ HEPES buffer ( $\mathrm{pH} 7.3$ ) was applied to a column of DEAE-Sepharose $(12 \times 5 \mathrm{~cm})$ equilibrated with $20 \mathrm{~mm}$-HEPES buffer $\left(\mathrm{pH} \mathrm{7.5)}\right.$ at $4{ }^{\circ} \mathrm{C}$. All the cytochrome bound to the column and elution was effected with a step-wise gradient of $\mathrm{NaCl}$ in the same buffer. The cytochromes were eluted in three major fractions (Fig. $1 a$ ). Each cytochrome fraction was concentrated over an Amicon PM-10 membrane (10 kDa cut-off) to a final volume of $5 \mathrm{ml}$ and each applied separately to a gel filtration column of Sephadex G-75 $(75 \times 2.5 \mathrm{~cm}$, medium grade) equilibrated in 20 mM-HEPES buffer (pH 7.5) containing $200 \mathrm{~mm}-\mathrm{NaCl}$, flowing upwards at $10 \mathrm{ml} \mathrm{h}^{-1}$ (Fig. 2). Each cytochrome fraction was then purified to homogeneity by ion-exchange chromatography on a Pharmacia Mono-Q anion-exchange column $(1 \mathrm{ml})$ using standard $\mathrm{NaCl}$ gradients $\left(17 \mathrm{mM} \mathrm{m}^{-1}\right.$ ) in $20 \mathrm{mM}$-HEPES buffer ( $\mathrm{pH} 7.5$ ). A final step of hydrophobic interaction chromatography was used for cytochrome $c_{553}$ and for the $46 \mathrm{kDa}$ heterodimer and the $150 \mathrm{kDa}$ complex. Cytochrome was loaded in $1.74 \mathrm{M}$-ammonium sulphate in 20 mM-HEPES buffer ( $\mathrm{pH} 7.5$ ) in a Pharmacia Phenyl-Superose column $(1 \mathrm{ml})$; elution was with a gradient of $1.74-0 \mathrm{M}$ in a total volume of $20 \mathrm{ml}$. Ammonium sulphate was removed by passage through Sephadex PD-10 columns.

Purification of the $45 \mathrm{kDa}$ dihaem cytochrome $c$ produced only under conditions of oxygen deficiency was achieved by the same method, but the starting material was 2 litres of periplasmic protein (1.6 g protein) produced from oxygen-deficient bacteria (Fig. 1).

\section{Results}

The periplasmic c-type cytochromes of two P. denitrificans strains

The strain used in this work is Paracoccus denitrificans NCIB 8944, which we first obtained from Oxford and which is the strain used by Ferguson and his colleagues (see Page \& Ferguson, 1989, 1990); we have designated this the Oxford strain. It was subsequently shown to differ in its cytochrome complement from the strain provided directly from the culture collection as NCIB 8944. It is not obvious what has led to the appearance of the Oxford strain. The NCIB strain had been routinely subcultured (anaerobically) every $2 \mathrm{~d}$ in liquid medium containing succinate and nitrate and had never been cultured on methanol.

The cytochromes from P. denitrificans NCIB 8944 (Oxford strain). The periplasmic proteins from bacteria grown aerobically on methanol were separated by anionexchange chromatography on DEAE-Sepharose into three fractions (Fig. 1a). SDS-PAGE followed by haem staining showed that the first fraction (A) contained a single haemoprotein, shown subsequently to be cytochrome $c_{550}(15 \mathrm{kDa})$. The second fraction (B) was a mixture of cytochrome $c_{552}(22 \mathrm{kDa})$ and $c_{553}(30 \mathrm{kDa})$. The three cytochromes in fractions $\mathrm{A}$ and $\mathrm{B}$ were similar to those described previously (Husain \& Davidson, 1986; Bosma et al., 1987b). The third fraction (C) contained two unexpected heamoprotein complexes, shown subsequently to have molecular masses of $46 \mathrm{kDa}$ and $150 \mathrm{kDa}$; these are discussed further below.

When this strain was grown aerobically with succinate as sole carbon and energy source no second peak was seen during ion-exchange chromatography and, as 


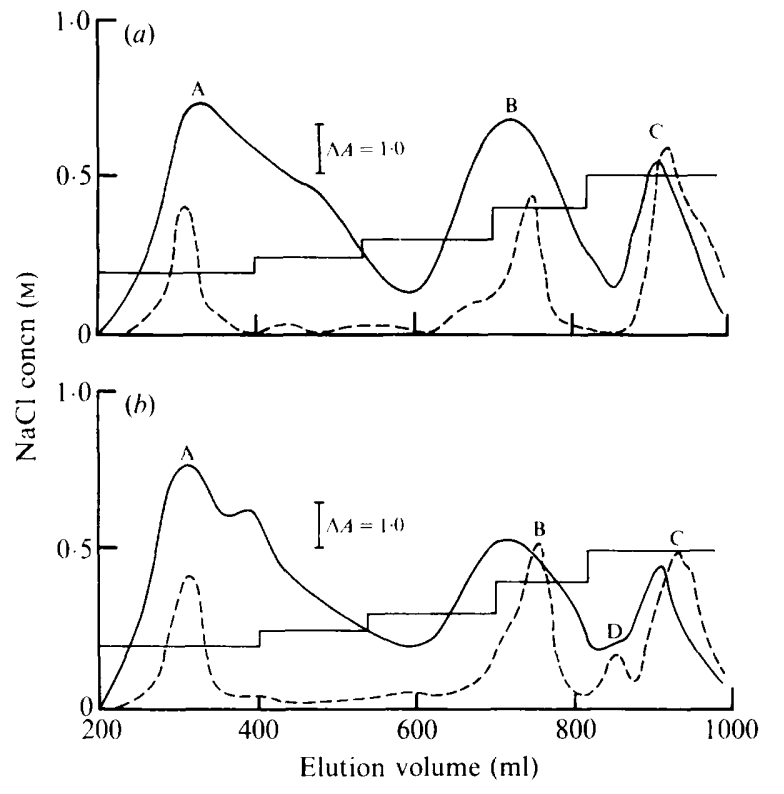

Fig. 1. Ion-exchange chromatography of the periplasmic fraction of $P$. denitrificans NCIB 8944 (Oxford strain). The periplasmic fraction was applied to a DEAE-Sepharose column in 20 mM-HEPES buffer $(\mathrm{pH}$ 7.5) and proteins were eluted by a stepwise gradient of $\mathrm{NaCl}$ as described in Methods. (a) From aerobically grown bacteria; $(b)$ from oxygen-deficient bacteria. - $-A_{280} ;-\cdots, A_{410}$.

expected from this, there were no $22 \mathrm{kDa}$ or $30 \mathrm{kDa}$ cytochromes, which are the cytochromes previously shown by Husain \& Davidson (1986) to be induced during methylotrophic growth. The two novel haemoprotein complexes observed in the third fraction $(C)$ were present after growth on methanol, or on succinate in either oxygen-sufficient or oxygen-deficient conditions.

The cytochromes from P. denitrificans NCIB 8944. By contrast with the Oxford strain, when this strain was grown aerobically on methanol no third peak of haemoproteins was observed during ion-exchange chromatography and SDS-PAGE of periplasmic proteins. All other cytochromes were present in very similar proportions and after purification were shown to be identical in all respects to those isolated from the Oxford strain (see below).

Purification and characterization of cytochromes $c_{550}$, $c_{552}$, and $c_{553}$ from periplasmic fractions from $P$. denitrificans (Oxford strain)

The purification was based on that described previously by Beardmore-Gray et al. (1983) and by Husain \& Davidson (1986). The first step was fractionation by ionexchange chromatography on DEAE-Sepharose (Fig. $1 a)$; this was followed by gel filtration of the major pooled peaks as shown in Fig. 2. Cytochromes $c_{550}, c_{552}$ and $c_{553}$ were then purified to homogeneity as described in Methods. The final yield of each cytochrome from 5.5

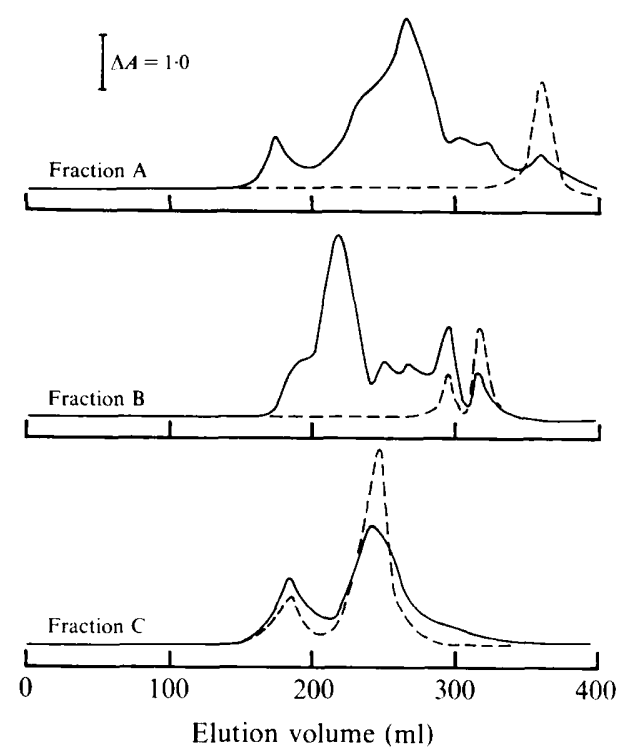

Fig. 2. Gel filtration of cytochrome fractions obtained by ionexchange chromotography of a periplasmic fraction of $\boldsymbol{P}$. denitrificans NCIB 8944 (Oxford strain). The cytochrome-containing fractions were purified by gel filtration on Sephadex G-75 as described in Methods. Fractions A, B and C correspond to the fractions labelled in Fig. 1. -,$A_{280} ;---, A_{410}$.

litres of periplasmic fraction $(2 \cdot 2 \mathrm{~g}$ protein) was as follows: cytochrome $c_{550}, 10 \mathrm{mg}$; cytochrome $c_{552}$, $13.9 \mathrm{mg}$; cytochrome $c_{553}, 0.75 \mathrm{mg}$.

Cytochrome $c_{550}$ was the same in all respects to that previously described: monohaem; pI about 4.5 ; molecular mass about $15 \mathrm{kDa}$; no reaction with $\mathrm{CO}$.

Cytochrome $c_{552}$ was clearly the same as that described as cytochrome $c_{551 i}$ by Husain \& Davidson (1986) and called cytochrome $c_{552}$ by Bosma et al. $(1987 b)$. We recorded the alpha absorption band of the reduced cytochrome as $551.6 \mathrm{~nm}$ and so refer to it for convenience as cytochrome $c_{552}$. It has the following characteristics: monohaem; pI about 3.5; molecular mass about $22 \mathrm{kDa}$; absorption coefficient of the ferrocytochrome at the alpha maximum $23.1 \mathrm{~mm}^{-1}$ $\mathrm{cm}^{-1}$; reaction with $\mathrm{CO}$ very slow, with less than $10 \%$ binding.

Cytochrome $c_{553}$ corresponded to the cytochrome $c_{553 \mathrm{i}}$ of Husain \& Davidson (1986) and the $30 \mathrm{kDa}$ cytochrome of Bosma et al. $(1987 \mathrm{~b})$. Its properties were as follows: monohaem, alpha absorption maximum $552.7 \mathrm{~nm}$; absorption coefficient of the ferrocytochrome at the alpha maximum $22.5 \mathrm{~mm}^{-1} \mathrm{~cm}^{-1}$; pI about 3.8 ; molecular mass about $30 \mathrm{kDa}$. Reaction with $\mathrm{CO}$ was rapid, $100 \%$ reaction occurring within 1 min of reaction with $\mathrm{CO}$. This cytochrome is thus likely to be the cytochrome responsible for the reaction with $\mathrm{CO}$ demonstrated by van Verseveld \& Stouthamer (1978) and subsequently referred to as cytochrome $c_{\mathrm{CO}}$. 
The $45 k D a$ cytochrome $c$ induced during oxygendeficient growth of $P$. denitrificans (Oxford strain)

When aerobic cultures on methanol were allowed to become oxygen deficient by decreasing the rate of shaking at the end of growth the pattern of periplasmic cytochromes changed. When these proteins were fractionated by ion-exchange chromatography very similar results to those shown in Fig. 1(a) were obtained except for a small additional peak (D) of material absorbing at $410 \mathrm{~nm}$ (Fig. $1 b$ ). The pooled fractions from this peak contained a haemoprotein that was absent from highly aerated bacteria. On SDS-PAGE there was a single haemoprotein of $45 \mathrm{kDa}$. The protein was purified by gel filtration on a calibrated column of Sephadex G-75, which indicated a native molecular mass of $45 \mathrm{kDa}$. The protein was then purified to homogeneity by further ionexchange chromatography on FPLC Mono-Q. After the initial DEAE-Sepharose chromatography of the periplasmic fraction, the purification achieved was threefold, with a yield of $64 \%$. At room temperature the absorption spectrum showed a peak at $552 \mathrm{~nm}$ and a shoulder at $555 \mathrm{~nm}(552 \mathrm{~nm}$ alpha band absorption coefficient $35.3 \mathrm{~mm}^{-1} \mathrm{~cm}^{-1}$ ). At $77 \mathrm{~K}$ the ferrocytochrome showed a double peak in the alpha region, with absorption maxima at $550.5 \mathrm{~nm}$ and $554 \mathrm{~nm}$ (Fig. 3). Both haems of the reduced cytochrome reacted with $\mathrm{CO}$ (30\% total binding), with troughs at $552 \mathrm{~nm}$ and $555 \mathrm{~nm}$, indicating that both haems were reacting with $\mathrm{CO}$. The induction of this cytochrome at low oxygen concentrations, its molecular mass and its spectral characteristics correspond to those of the $45 \mathrm{kDa}$ dihaem haemoprotein observed by Bosma et al. (1987b). From their preliminary observation, they suggested that the absorption spectrum indicated a dihaem protein having both haem $c$ and protohaem (haem $b$ ) prosthetic groups. However, pyridine haemochrome spectra of our cytochrome indicated that there is no protohaem, but two molecules of haem $c$ per molecule of cytochrome $c$. It should be nuted that this monomeric, dihaem cytochrome $c$ is completely different from the $46 \mathrm{kDa}$ heterodimer described below.

The large cytochrome c complex (150kDa) of $P$. denitrificans (Oxford strain)

As shown in Fig. 2, gel filtration of the third peak (C) obtained during ion-exchange chromatography of the periplasmic fraction (Fig. $1 a$ ) indicated that there were two haemoprotein complexes in this strain. The larger of these (about $150 \mathrm{kDa}$ ) was present in only small amounts. It was purified by ion-exchange chromatography on FPLC Mono-Q and by hydrophobic chromatography on FPLC Phenyl-Superose. SDS-PAGE (7.5-

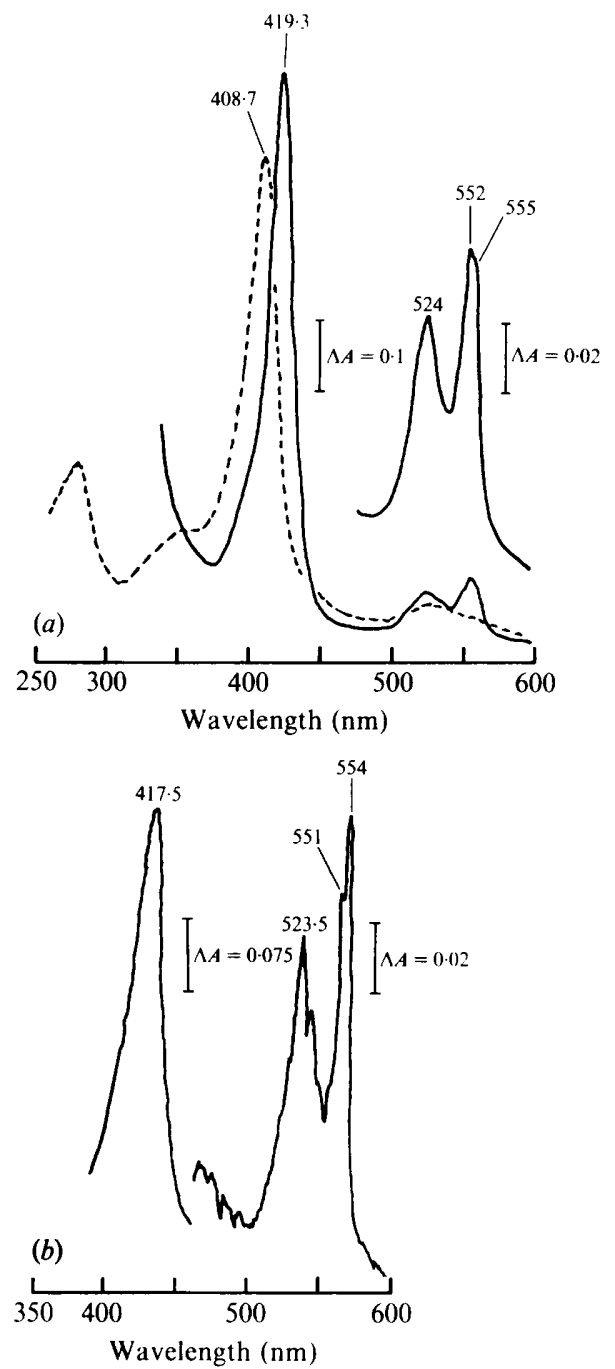

Fig. 3. Absorption spectra of the $45 \mathrm{kDa}$ dihaem cytochrome $c$ from $P$. denitrificans (Oxford strain) grown under oxygen-deficient conditions. (a) Spectra measured at $20^{\circ} \mathrm{C}$ with $25 \mu \mathrm{M}$-cytochrome. (b) Spectrum measured at $77 \mathrm{~K}, 2 \mathrm{~mm}$ light path, $0.5 \mathrm{~nm}$ bandwidth, $1.3 \mu \mathrm{M}$ cytochrome. - , Cytochrome reduced with dithionite; - - , untreated ferricytochrome.

$15 \%$, linear gradient) showed that the complex consisted of a single major non-haem protein (about $85 \%$ of the total protein) plus four haemoproteins of $28,33,41$ and $47 \mathrm{kDa}$. The complex ran as a single band during analytical gel filtration on Superose-12. Identical results were obtained in HEPES buffer (pH 7.5) containing $1 \mathrm{M}$ $\mathrm{NaCl}$. Non-denaturing PAGE at $\mathrm{pH} 8.8$ separated the complex into three haemoprotein bands plus the nonhaem protein that did not enter the gel matrix, indicating a strongly basic nature. The spectrum of the complex showed a single peak at about $552 \mathrm{~nm}$ in the reduced form at room temperature, and $550.5 \mathrm{~nm}$ at $77 \mathrm{~K}$. The absorption coefficient at $552 \mathrm{~nm}$ was very high $\left(157 \mathrm{~mm}^{-1} \mathrm{~cm}^{-1}\right)$, consistent with a large number of 
haems per molecule, and this was confirmed by preparation of the pyridine haemochrome which showed that there were 6-7 mol of haem $c$ per mole of complex. Reaction with $\mathrm{CO}$ was rapid and suggested that about 5 moles of haem were reacting with $\mathrm{CO}$. When run on a shallow gradient ( $\left.13.5 \mathrm{~mm} \mathrm{~min}^{-1}\right)$ on Mono-Q in $20 \mathrm{~mm}^{-}$ HEPES buffer ( $\mathrm{pH} 7.5$ ) the complex ran as a broad band, and SDS-PAGE showed that fractions from opposite sides of the peak contained the same proportion of the non-haem protein but the ratios of the haem proteins were different.

The novel $46 \mathrm{kDa}$ heterodimeric cytochrome $c$ of $P$. denitrificans (Oxford strain)

This cytochrome was the major cytochrome in the third haemoprotein peak (C) during initial ion-exchange chromatography (Fig. 1a). Gel filtration was used to purify it further (Fig. 2); this indicated a native molecular mass of $46 \mathrm{kDa}$. The cytochrome was purified to homogeneity by using FPLC Mono-Q and PhenylSuperose columns. After purification, it ran as a single peak during analytical gel filtration on FPLC Superose12 , confirming the native molecular mass of $46 \mathrm{kDa}$. It constituted about $25 \%$ of the total periplasmic cytochrome $c$ of the Oxford strain but was completely absent from the original NCIB strain 8944.

The absorption spectrum of the ferrocytochrome at room temperature showed peaks at $417.5,523.5$ and $552.7 \mathrm{~nm}$ (Fig. 4); the absorption coefficient of the alpha band was $64 \mathrm{~mm}^{-1} \mathrm{~cm}^{-1}$. The spectrum was unusual in the high ratio of absorbance in the alpha band compared with the beta band. Pyridine haemochrome spectra confirmed that the only type of haem present was haem $c$ and that there were 4-5 molecules of haem per molecule of complex. There was about $35 \%$ reaction with $\mathrm{CO}$, the $\mathrm{CO}$ difference spectrum of the complex showing a typical trough at $552.7 \mathrm{~nm}$. The behaviour of the complex in ion-exchange chromatography suggested that the cytochrome is an acidic protein with an isoelectric point less than $3 \cdot 5$.

Separation of the subunits of the $46 \mathrm{kDa}$ heterodimeric cytochrome $c$. The behaviour of this cytochrome on SDSPAGE $(7.5-15 \%$ gradient) was unusual. In reducing conditions (presence of mercaptoethanol) only two protein-staining bands were seen $(30 \mathrm{kDa}$ and $16 \mathrm{kDa})$; and both these bands stained for haem. In the absence of mercaptoethanol a third haemoprotein band was seen $(15 \mathrm{kDa})$ which was about $20 \%$ of the intensity of the original $16 \mathrm{kDa}$ band, which had diminished by about $20 \%$. These results suggest that this cytochrome $c$ is a heterodimer consisting of two subunits $(30 \mathrm{kDa}$ and $16 \mathrm{kDa})$, each of which contains haem. During SDS-
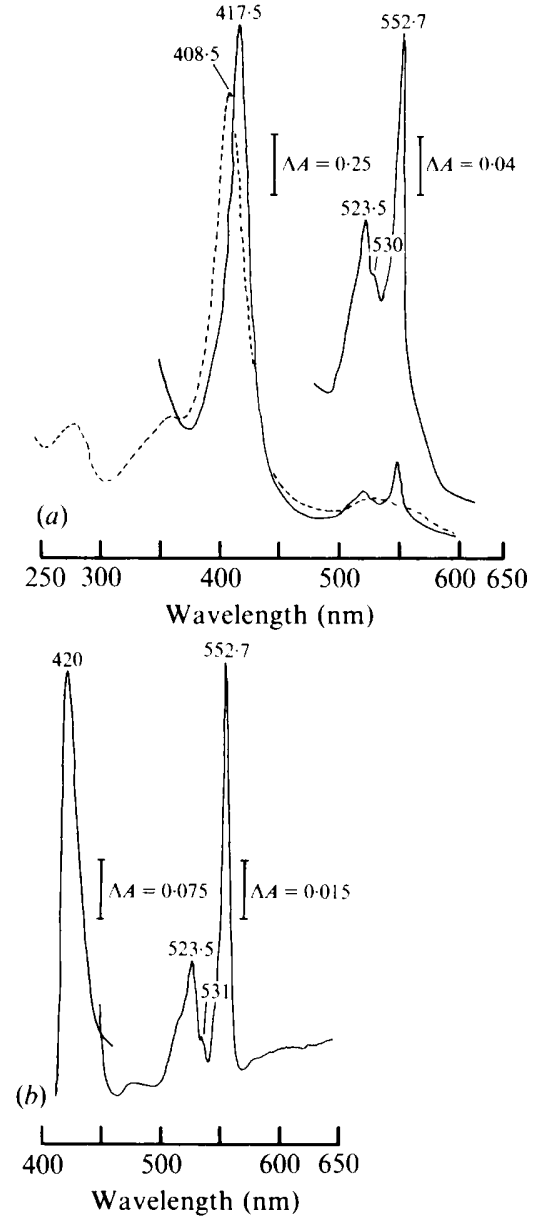

Fig. 4. Absorption spectra of the $46 \mathrm{kDa}$ cytochrome $c$ heterodimer. Cytochrome was either reduced with dithionite (- - ), or oxidized with ammonium persulphate (--)). (a) Absorption spectra $(5.5 \mu \mathrm{M}$ cytochrome). (b) Reduced minus oxidized difference spectrum $(2 \cdot 7 \mu \mathrm{M}-$ cytochrome). Spectra were measured at $20^{\circ} \mathrm{C}$.

PAGE the smaller subunit is presumably able to form a disulphide bridge leading to an apparently smaller peptide of $15 \mathrm{kDa}$ which can be reduced by mercaptoethanol). The native molecular mass $(46 \mathrm{kDa})$ was confirmed by its properties during gel filtration on Sephadex G-75 and by gel filtration on a Pharmacia Superose- 12 column. It was shown by Western blotting that neither subunit reacted with antibody raised to cytochrome $c_{550}$ of $P$. denitrificans.

Analytical gel filtration on a Pharmacia Superose-12 FPLC (24 ml) column was used to investigate further the properties of the dimeric cytochrome. There was no dissociation into subunits during gel filtration in HEPES buffer ( $\mathrm{pH} 7.5$ ) containing $1.0 \mathrm{M}-\mathrm{NaCl}$. By contrast, the dimer was dissociated into two subunits at $\mathrm{pH}$ values greater than 11, complete dissociation occurring at $\mathrm{pH} 12$ into subunits of $30 \mathrm{kDa}$ and $16 \mathrm{kDa}$ (Fig. 5). No 


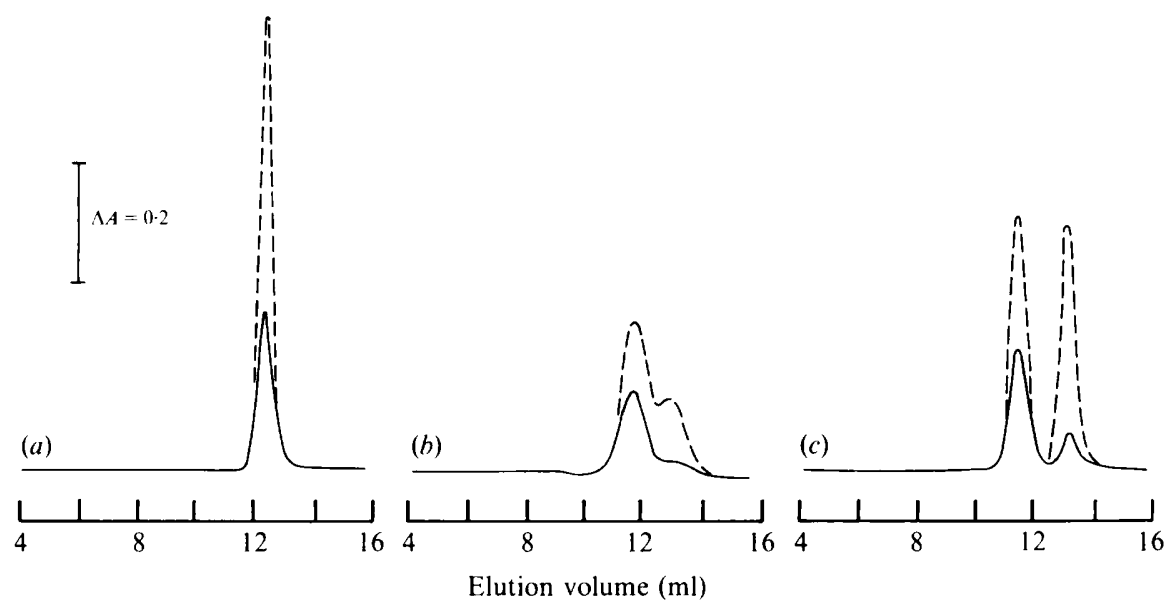

Fig. 5. Dissociation into subunits at high $\mathrm{pH}$ values of the $46 \mathrm{kDa}$ cytochrome $c$ heterodimer. Dissociation of the dimer $(50 \mu \mathrm{g})$ was achieved by passage through a Superose gel filtration column in $20 \mathrm{~mm}$-buffer containing $200 \mathrm{~mm}-\mathrm{NaCl}$. (a) Gel filtration in the range $\mathrm{pH} 7.5-10.0 ;(b)$ gel filtration at $\mathrm{pH} 11 ;(c)$ gel filtration at $\mathrm{pH} 12.0$. The elution of the protein was measured at $280 \mathrm{~nm}(-)$ or at $405 \mathrm{~nm}(---)$. The following buffers were used: HEPES (pH 7.5); Tris (pH 9); CHES (pH 10); CAPS (pH 11); phosphate (pH 12).

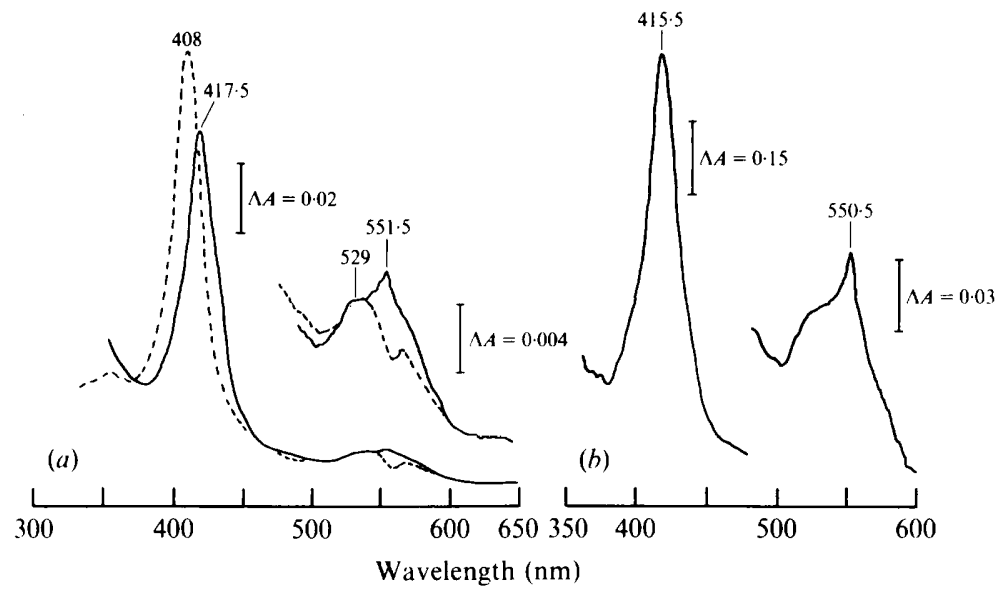

Fig. 6. Absorption spectra of the dissociated $30 \mathrm{kDa}$ subunit of the $46 \mathrm{kDa}$ heterodimer. (a) Spectra measured at $20^{\circ} \mathrm{C}$, with $0 \cdot 3 \mu \mathrm{M}$ cytochrome. (b) Spectrum measured at $77 \mathrm{~K}, 2 \mathrm{~mm}$ light path, $0.5 \mathrm{~nm}$ bandwidth, $0.3 \mu \mathrm{M}$-cytochrome. —- Cytochrome reduced with dithionite; - - , untreated ferricytochrome.

dissociation occurred between $\mathrm{pH} 5$ and $\mathrm{pH} \mathrm{10,} \mathrm{and} \mathrm{the}$ protein precipitated in the column at $\mathrm{pH} 4$. After gel filtration at high $\mathrm{pH}$ the isolated subunits were adjusted to $\mathrm{pH} 7.5$ prior to further investigation. During SDSPAGE the dissociated subunits behaved exactly as described for SDS-PAGE of the untreated enzyme; the $16 \mathrm{kDa}$ subunit showed some disulphide formation as described above. When the subunits were separated by gel filtration at $\mathrm{pH} 12$ and the protein estimated for each peak by the methods of Bradford (1976) and Smith et al. (1988), the ratios calculated for the two subunits were $1 \cdot 2$ and $1 \cdot 16$. This suggests that each heterodimer contains one molecule of each type of subunit, and this corresponds perfectly with the native molecular mass of $46 \mathrm{kDa}$ as estimated by gel filtration on Superose-12 and Sephadex G-75.
An alternative method for separation into subunits was treatment with guanidinium chloride at $\mathrm{pH} 7.5$ in $50 \mathrm{mM}$-HEPES buffer. Cytochrome was incubated for up to $3 \mathrm{~h}$ in $3 \mathrm{M}$-guanidinium chloride and passed through the Superose- 12 column equilibrated with the same buffer containing $0.5 \mathrm{M}$-guanidinium chloride. The two peaks obtained during this gel filtration process contained subunits that behaved on SDS-PAGE exactly as previously described.

Absorption spectra of the subunits of the $46 \mathrm{kDa}$ heterodimeric cytochrome c. Fig. 6 shows the spectrum of the isolated $30 \mathrm{kDa}$ subunit, The spectrum of the ferricytochrome $c$ is typical of a low-spin cytochrome but the spectrum of the ferrocytochrome is more typical of a high-spin cytochrome $c$, with a poorly defined alpha 


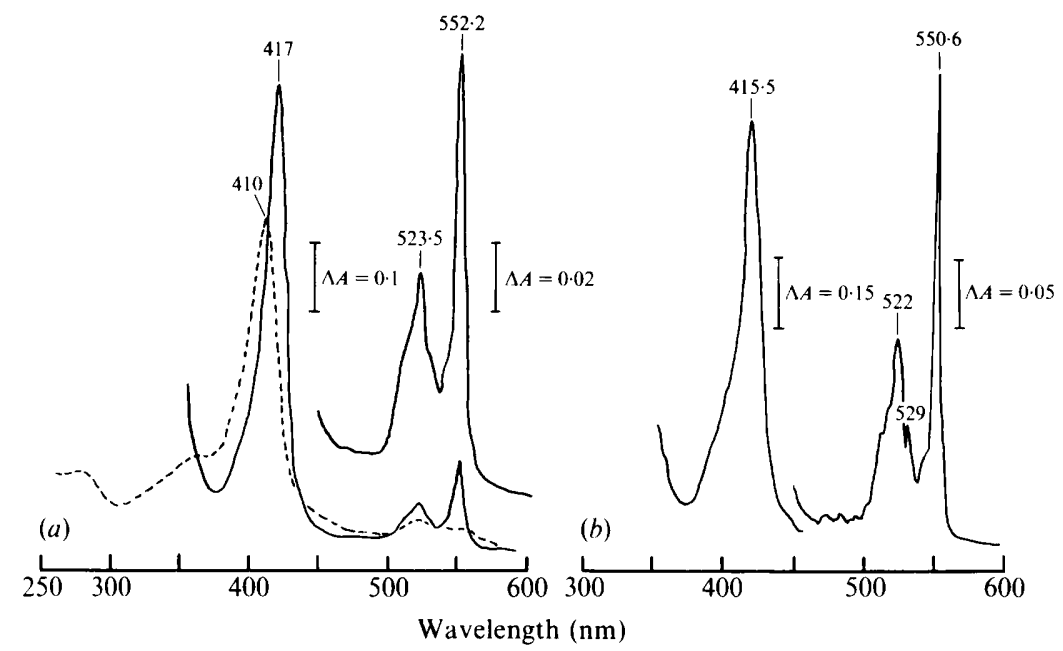

Fig. 7. Absorption spectra of the dissociated $16 \mathrm{kDa}$ subunit of the $46 \mathrm{kDa}$ heterodimer. (a) Spectra measured at $20^{\circ} \mathrm{C}$ with $2 \cdot 7 \mu \mathrm{M}$ cytochrome. (b) Spectrum measured at $77 \mathrm{~K}, 2 \mathrm{~mm}$ light path, $0.5 \mathrm{~nm}$ bandwidth, $2.7 \mu \mathrm{M}$-cytochrome. - , Cytochrome reduced with dithionite; -- - , untreated ferricytochrome.

peak near $550 \mathrm{~nm}$ and no defined beta peak. There was some absorption above $560 \mathrm{~nm}$ which presumably corresponds to the absorption in this region seen in the heterodimer (Fig. 4). There was no absorption in the near-infrared region (about $700 \mathrm{~nm}$ ), indicating that there is no methionine sixth ligand to the haem iron in this cytochrome. When the $\mathrm{pH}$ of the reduced subunit was raised to 9 the subunit became rapidly oxidized. After returning to $\mathrm{pH} 7 \cdot 5$, reduction with dithionite led to cytochrome with a spectrum typical of the reduced form, indicating that the isolated $30 \mathrm{kDa}$ subunit had become autoxidized at high $\mathrm{pH}$ values. Addition of cyanide to the oxidized or reduced forms had no effect on the spectrum of the $30 \mathrm{kDa}$ subunit over the $\mathrm{pH}$ range 7.5-12. However, it should be noted that raising the $\mathrm{pH}$ of this subunit led to 'damage' and subsequent 'conversion' to a low-spin cytochrome (see below). The subunit showed typical alpha and beta peaks, and the absorbance in the Soret region was lower in the oxidized form than in the reduced form; and there was no absorbance at $560 \mathrm{~nm}$ as seen before denaturation at high $\mathrm{pH}$.

Fig. 7 shows that the spectra of the isolated small (16 kDa) subunit are typical of low-spin $c$-type cytochromes with an alpha absorption band at $552.2 \mathrm{~nm}$. An unusual feature, however, was the high alpha/beta ratio of absorbance (about 3), which corresponds to the exceptionally high ratio observed in the heterodimer. There was no absorption by the ferricytochrome in the $700 \mathrm{~nm}$ region, indicating that this subunit also has no methionine as its sixth ligand.

When the spectra of equimolar amounts of the separated subunits were added the resultant spectra were very similar to those of the undissociated heterodimer.
Haem content, $\mathrm{CO}$ reactivity and redox potential of the isolated subunits of the heterodimer. Both subunits gave typical cytochrome $c$ pyridine haemochrome spectra. The values for the $30 \mathrm{kDa}$ subunit indicated three haems per molecule (measured values of $3 \cdot 1$ and $3 \cdot 3$ ). The values for the small ( $16 \mathrm{kDa})$ subunit indicated two haems per molecule (measured values 1.8 and 1.83). The values for the undissociated dimer $(46 \mathrm{kDa})$ indicated five haems per molecule (measured values $4 \cdot 6,4 \cdot 7$ and $4 \cdot 8$ ).

Both subunits reacted with $\mathrm{CO}$ when in the reduced form. The large subunit reacted completely within $5 \mathrm{~min}$, the spectrum indicating reaction of three haems per molecule. The small subunit gave complete reaction within $1.5 \mathrm{~min}$, the spectrum indicating reaction of two haems per molecule. Whereas the $\mathrm{CO}$ difference spectrum of the small subunit was typical of that of lowspin cytochromes, that of the large subunit was indicative of a predominantly high-spin cytochrome $c$ (Fig. 8). These results demonstrated that all of the haems in the isolated subunits are able to react with $\mathrm{CO}$ whereas the reaction in the untreated heterodimer is slower and less complete.

The midpoint potential of the large subunit could not be measured because of the small difference in absorption between the reduced and oxidized forms. The potential of the small $(16 \mathrm{kDa})$ subunits was $+188 \mathrm{mV}$, a value slightly lower than that measured in the native heterodimer $(205 \mathrm{mV})$. As with the native cytochrome, the redox titration was characteristic of a single electrontransfer reaction.

Reconstitution of the heterodimer from subunits. Subunits were separated at $\mathrm{pH} 12$ and immediately transferred to 


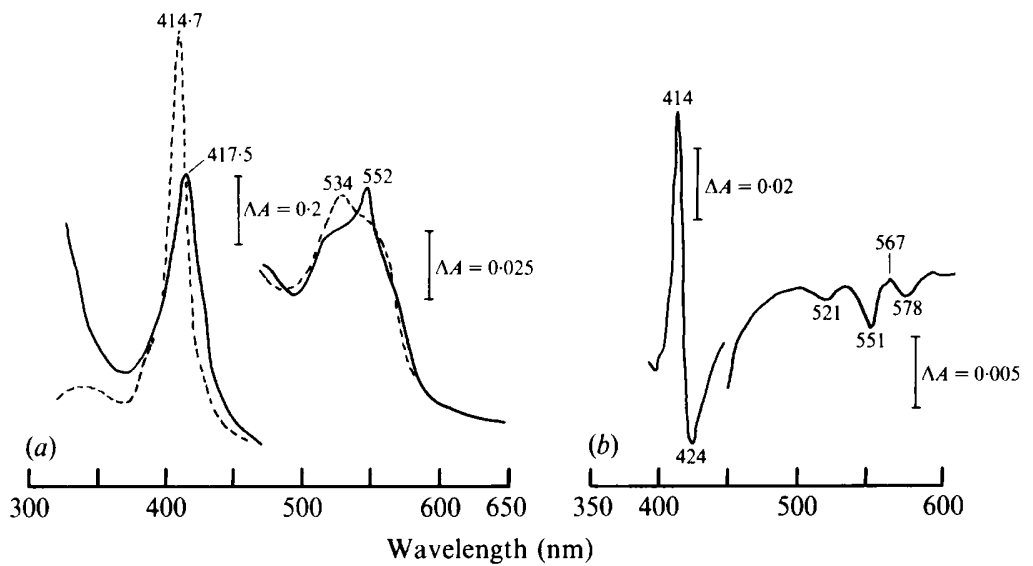

Fig. 8. Reaction of the large subunit $(30 \mathrm{kDa})$ of the $46 \mathrm{kDa}$ cytochrome $c$ heterodimer with $\mathrm{CO}$. $(a)-$, Dithionite-reduced cytochrome $(2 \cdot 8 \mu \mathrm{M}) ;---$, reduced cytochrome after reaction with $\mathrm{CO}$ for $5 \mathrm{~min}$. (b) (Reduced plus $\mathrm{CO}$ )-minus-reduced spectrum obtained with $0.6 \mu \mathrm{M}$-cytochrome and 5 min reaction with $\mathrm{CO}$.

buffer at $\mathrm{pH} 7.5$ by gel filtration in PD-10 columns. The solutions were concentrated and a $1: 1$ molar mixture passed through Superose-12 in 20 mM-HEPES buffer (pH 7.5) containing $200 \mathrm{~mm}-\mathrm{NaCl}$. A single peak was eluted, corresponding to a molecular mass of $46 \mathrm{kDa}$. The absorption spectrum of the reconstituted dimer was almost identical to that of the undissociated form, the absorption coefficients being within $5 \%$ of those of the initial heterodimer. The spectrum of the ferrocytochrome showed the high alpha/beta ratio, the absorbance above $560 \mathrm{~nm}$ and the very sharp alpha peak of the original heterodimer. The characterisitics of the gel patterns after SDS-PAGE and non-denaturing PAGE were exactly the same as for the original undissociated dimer. When the large subunit was maintained at $\mathrm{pH} 12$ for $3 \mathrm{~h}$ before lowering the $\mathrm{pH}$ to 7.5 no reconstitution occurred, indicating that prolonged exposure damaged this subunit. This was not the case with the small subunit: exposure of this subunit to high $\mathrm{pH}$ for $3 \mathrm{~h} \mathrm{did}$ not diminish its potential for reconstitution with freshly prepared large subunit.

Reconstitution of complete dimer could also be achieved by mixing small subunit prepared in guanidinium chloride (as described above) with fresh large subunit from $\mathrm{pH} 12$ treatment. Guanidinium chloride damaged the large subunit so that it would no longer reconstitute with the small subunit. These results thus demonstrate that the large subunit is susceptible to damage by high $\mathrm{pH}$ or denaturing agent whereas the small subunit is relatively stable.

\section{Reaction of $M D H$ with cytochrome c}

All the cytochromes described in the present work were tested as electron acceptors from MDH purified from the periplasm of $P$. denitrificans (Oxford strain). The assay used was that used for the first demonstration that cytochrome $c_{\mathrm{L}}$ is the electron acceptor for $\mathrm{MDH}$ in other methylotrophs (Beardmore-Gray et al., 1983). Reduction of cytochrome $c$ alone was tested, but for determination of formaldehyde accumulation a large excess of horse heart cytochrome $c$ was included as terminal electron acceptor. The only cytochrome reduced by MDH was cytochrome $c_{552}(22 \mathrm{kDa})$, also called cytochrome $c_{551 \mathrm{i}}$. In the absence of methanol no formaldehyde accumulated but, as found previously for other systems, there was some cytochrome reduction in the absence of added methanol. The stoichiometry of the reaction was one formaldehyde produced for two molecules of cytochrome reduced. When formaldehyde replaced methanol as substrate, two molecules of cytochrome were reduced for every formaldehyde oxidized. The $K_{\mathrm{m}}$ for cytochrome $c_{\mathrm{L}}$ was $0.8 \mu \mathrm{M}$ and the velocity at substrate saturation, $V$, was $2.4 \mathrm{nmol} \min ^{-1}(\mathrm{nmol} \mathrm{MDH})^{-1}$. These values are very close to those measured for the proteins from $M$. extorquens AM1 and $M$. methylotrophus (BeardmoreGray et al., 1983).

None of the other cytochromes described in the present work was able to replace cytochrome $c_{552}$ as electron acceptor for MDH. Of special importance is the observation that no reduction of cytochrome, nor production of formaldehyde, was observed when using cytochrome $c_{553}$, the CO-reactive cytochrome previously assumed to be the specific electron acceptor for MDH.

\section{Discussion}

The most unexpected conclusion of the present paper is that cytochrome $c_{553}$ (or cytochrome $c_{\mathrm{CO}}$ ) is not the electron acceptor for $\mathrm{MDH}$; the sole electron acceptor is the periplasmic $22 \mathrm{kDa}$ cytochrome (cytochrome $c_{551 \mathrm{i}}$ or 
$c_{552}$ ) which is one of the two $c$-type cytochromes induced during growth on methanol. The previous assumption that cytochrome $c_{553}$ is the electron acceptor was based on the observation that it was also induced during growth on methanol, and on the assumption that CO-reactivity is in some way diagnostic of the methanol-linked cytochrome $c$ of other methylotrophs. However, as has been emphasized previously (Anthony, 1982, 1986), there has never been any evidence that this feature is important to the physiological function of these cytochromes. This work raises the question of the function of cytochrome $c_{553}$ (or cytochrome $c_{\mathrm{CO}}$ ).

The demonstration that the $22 \mathrm{kDa}$ cytochrome $c_{552}$ is the electron acceptor for MDH directs attention to the previously published conclusion that this cytochrome $c$ mediates electron transfer from amicyanin, which is the electron acceptor for the quinoprotein methylamine dehydrogenase (Husain \& Davidson, 1986; Gray et al., 1986). All three small periplasmic cytochromes $\left(c_{550}\right.$, $c_{552}$ and $c_{553}$ ) were able to react with amicyanin in this system, but the reaction rate with cytochrome $c_{552}$ was greatest (Husain \& Davidson, 1986). As with all discussions of electron flow in periplasmic systems it is difficult, however, to be certain about which is the 'physiological' sequence of redox mediators when more than one is able to react (Anthony, 1988, 1989; Ferguson, 1988). In another methylotroph (Methylobacterium extorquens) a mutant lacking the $\mathrm{MDH}$-specific cytochrome was able to grow well on methylamine, suggesting that cytochrome $c_{552}$ plays no role in methylamine metabolism in $P$. denitrificans. It will clearly be necessary to isolate and characterize mutants of $\boldsymbol{P}$. denitrificans lacking each of these cytochromes in order to elucidate the pathways of periplasmic electron transport. One such mutant has recently been described: it specifically lacks cytochrome $c_{550}$ and is still able to grow on methylamine, albeit at a lower rate, supporting the suggestion that this cytochrome usually plays some role in methylamine oxidation (van Spanning et al., 1990). As cytochrome $c_{550}$ is usually considered to be the donor to the oxidase, it is clear from this result that some alternative route from amicyanin to the oxidase is possible.

Work with mutants specifically lacking each type of cytochrome $c$ is also likely to be essential for evaluating the suggestion (Bosma et al., 1987a, b) that the soluble cytochrome $c_{552}$ (now known to be the electron acceptor for $\mathrm{MDH}$ ) may be the same as the membrane cytochrome $c_{552}$ that has been proposed as part of a ubiquinol oxidase complex (Berry \& Trumpower, 1985). A similar suggestion has been made for the membrane cytochrome $c$ of the obligate methylotroph Methylophilus methylotrophus (Froud \& Anthony, 1984). This would raise a problem with respect to regulation of synthesis of cytochrome $c_{552}$ in the facultative methylotroph $P$. denitrificans, because the soluble form is induced only during growth on methanol (not succinate) but it is present on membranes at a high level when cells are grown on succinate (Bosma et al., 1987a; Berry \& Trumpower, 1985).

The monomeric cytochrome of $45 \mathrm{kDa}$ that was induced at the end of growth when the oxygen supply was insufficient clearly corresponds to the cytochrome induced in aerobic and oxygen-limited conditions described by Bosma et al. $(1987 a, b)$. The demonstration that this is a dihaem cytochrome $c$ rather than being a cytochrome $b c$ as suggested by Bosma et al. (1987b) is particularly relevant in relation to the suggestion that it corresponds to a cytochrome of similar size which might be involved as a cytochrome oxidase (co) component present in membranes of these bacteria.

A most unexpected finding of this work is the presence in one strain of $P$. denitrificans of a remarkable $46 \mathrm{kDa}$ cytochrome $c$ heterodimer which could be reversibly dissociated into its constituent monomers. The smaller subunit $(16 \mathrm{kDa})$ bears two haems, each having a lowspin character. The second subunit $(30 \mathrm{kDa})$ has, by contrast, three molecules of haem which appear to be low-spin in the oxidized state and high-spin in the reduced state. Cytochrome $c$ with these spectral (and spin) characteristics has been described recently in another methylotroph, Methylophilus methylotrophus (Santos \& Turner, 1988; Berry et al., 1990). This cytochrome (called cytochrome $c^{\prime \prime}$ ) differs from the $30 \mathrm{kDa}$ subunit of the heterodimer described here in being a small $(16 \mathrm{kDa})$ monomer and in being able to react with cyanide at high $\mathrm{pH}$. It was similar in reacting with $\mathrm{CO}$, and in having no methionine ligand and no absorption at about $630 \mathrm{~nm}$, which is characterisitic of some other high-spin cytochromes. The description of this cytochrome partially confirms the prediction of Santos \& Turner (1988) that other methylotrophs may contain cytochromes with unusual spin states, but as with many other unusual bacterial $c$-type cytochromes, none of the work reported here sheds any light on its function.

This work was supported by the SERC by provision of a research studentship to A. R. L.

\section{References}

Alefounder, P. R. \& Ferguson, S. J. (1981). A periplasmic location for methanol dehydrogenase from Paracoccus denitrificans: implications for proton pumping by cytochrome $a a_{3}$. Biochemical and Biophysical Research Communications 98, 778-784.

ANTHONY, C. (1982). The Biochemistry of Methylotrophs. London: Academic Press.

ANTHONY, C. (1986). The bacterial oxidation of methane and methanol. Advances in Microbial Physiology 27, 113-210.

ANTHONY, C. (1988). Quinoproteins and energy transduction. In Bacterial Energy Transduction, pp. 293-316. Edited by C. Anthony. London: Academic Press. 
ANTHONY, C. (1989). Quinoproteins in C-1 dissimilation by bacteria. Antonie van Leeuwenhoek 56, 13-23.

ANTHONY, C. \& ZATMAN, L. J. (1967). The microbial oxidation of methanol: purification and properties of the alcohol dehydrogenase of Pseudomonas sp. M27. Biochemical Journal 104, 953-959.

Beardmore-Gray, M., O'KeEFfe, D. T. \& ANTHony, C. (1983). The methanol:cytochrome $c$ oxidoreductase activity of methylotrophs. Journal of General Microbiology 129, 923-933.

BERRY, E. A. \& TRUMPOWER, B. L. (1985). Isolation of ubiquinol oxidase from Paracoccus denitrificans and resolution into cytochrome $b c_{1}$ and cytochrome $c-a a_{3}$ complexes. Journal of Biological Chemistry 260, 2458-2467.

Berry, M. J., George, S. J., Thomson, A. J., Santos, H. \& Turner, D. L. (1990). Cytochrome $c^{\prime \prime}$ isolated from Methylophilus methylotrophus. An example of bis-histidine-co-ordinated $\mathrm{Fe}^{3+}$ haem, with near-perpendicular orientation of the ligands. Biochemical Journal 270, 413-417.

Bosma, G., Braster, M., Stouthamer, A. H. \& van Verseveld, H. W. (1987a). Isolation and characterization of ubiquinol oxidase complexes from Paracoccus denitrificans cells cultured under various limiting growth conditions in the chemostat. European Journal of Biochemistry 165, 657-665.

Bosma, G., Braster, M., Stouthamer, A. H. \& van Verseveld, H. W. (1987b). Subfractionation and characterization of soluble $c^{-}$ type cytochromes from Paracoccus denitrificans cultured under various limiting conditions in the chemostat. European Journal of Biochemistry 165, 665-670.

BRADFORD, M. (1976). A rapid and sensitive method for the quantitation of microgram quantities of protein utilizing the principle of protein-dye binding. Analytical Biochemistry 72, 248254.

Davidson, V. L. \& Kumar, M. A. (1989). Cytochrome $c$-550 mediates electron transfer from inducible periplasmic $c$-type cytochromes to the cytoplasmic membrane of Paracoccus denitrificans. FEBS Letters 245, 271-273.

DAY, D. J. \& ANTHONY, C. (1990). Methanol dehydrogenase from Methylobacterium extorquens AM1. Methods in Enzymology 188, 210216

DAY, D. J., NUNN, D. N. \& ANTHONY, C. (1990). Characterization of a novel soluble $c$-type cytochrome in a moxD mutant of Methylobacterium extorquens AM1. Journal of General Microbiology 136, 181-188.

DutTon, P. L. (1978). Redox potentiometry: determination of midpoint potentials of oxidation-reduction components of biological electron transfer systems. Methods in Enzymology 54, 411-434.

Ferguson, S. J. (1988). Periplasmic electron transport reactions. In Bacterial Energy Transduction, pp. 141-182. Edited by C. Anthony. London: Academic Press.

Froud, S. J. \& ANThony, C. (1984). The roles of cytochrome $c$ in membranes of Methylophilus methylotrophus. Journal of General Microbiology 130, 3319-3325.

FunRHoP, J. H. \& SMITH, K. M. (1975). Laboratory methods. In Porphyrins and Metalloporphyrins, pp. 757-869. Edited by K. M. Smith. Amsterdam: Elsevier.

Gray, K. A., Knaff, D. B., Husain, M. \& Davidson, V. L. (1986). Measurement of the oxidation-reduction potentials of amicyanin and $c$-type cytochromes from Paracoccus denitrificans. FEBS Letters 207, 239-242.

Harms, N., de Vries, G., Maurer, K., HoogendiJk, J. \& StouthAMER, A. H. (1987). Isolation and nucleotide sequence of the methanol dehydrogenase structural gene from Paracoccus denitrifcans. Journal of Bacteriology 169, 3969-3975.

Husain, M. \& Davidson, V. L. (1986). Characterization of two inducible periplasmic $c$-type cytochromes from Paracoccus denitrificans. Journal of Biological Chemistry 261, 8577-8580.

KORNBerG, H. L. \& MORRIs, J. G. (1965). The utilization of glycollate by Micrococcus denitrificans: the beta hydroxyaspartate pathway. Biochemical Journal 95, 557-586.

LAEMmLI, U. K. (1970). Cleavage of structural proteins during the assembly of the head of bacteriophage T4. Nature, London 227, 680685 .

Lambin, P., Rochu, D. \& Fine, J. M. (1976). A new method for determination of molecular weights of proteins by electrophoresis across a sodium dodecyl sulphate polyacrylamide gradient gel. Analytical Biochemistry 74, 567-575.

NunN, D. N. \& ANTHONY, C. (1988). The nucleotide sequence and deduced amino acid sequence of the cytochrome $c_{\mathrm{L}}$ gene of Methylobacterium extorquens AM1: a novel class of c-type cytochromes. Biochemical Journal 256, 673-676.

Page, M. D. \& Ferguson, S. J. (1989). A bacterial $c$-type cytochrome can be translocated to the periplasm as an apo form; the biosynthesis of cytochrome $c d_{1}$ (nitrate reductase) from Paracoccus denitrificans. Molecular Microbiology 3, 653-631.

PAGE, M. D. \& Ferguson, S. J. (1990). A po-forms of cytochrome c-550 and cytochrome $c d_{1}$ are translocated to the periplasm of Paracoccus denitrificans in the absence of haem incorporation caused by either mutation or inhibition of haem synthesis. Molecular Microbiology 4, 1181-1192.

Raitio, M., Pispa, J. M., Metso, T \& Saraste, M. (1990). Are there isoenzymes of cytochrome $c$ oxidase in Paracoccus denitrificans? FEBS Letters 261, 431-435.

SANTOS, H. \& TURNER, D. L. (1988). Characterization and NMR studies of a novel cytochrome $c$ isolated from Methylophilus methylotrophus which shows a redox-linked change of spin state. Biochimica et Biophysica Acta 954, 277-286.

Smith, A., Hill, S. \& ANTHONY, C. (1988). A haemoprotein is not involved in the control by oxygen of enteric nitrogenase synthesis. Journal of General Microbiology 134, 1499-1507

van Spanning, R. J. M., Wansell, C., Harms, N., Oltmann, L. F. \& Stouthamer, A. H. (1990). Mutagenesis of the gene encoding cytochrome c-550 of Paracoccus denitrificans and analysis of the resultant physiological effects. Journal of Bacteriology 172, 986-996.

Thomas, P. E., RYAN, D. \& LEVIN, W. (1986). An improved staining procedure for the detection of the peroxidase activity of cytochrome P450 on SDS-polyacrylamide gels. Analytical Biochemistry 75, 168176.

van Verseveld, H. W. \& Stouthamer, A. H. (1978) Electron transport chain and coupled oxidative phosphorylation in methanolgrown Paracoccus denitrificans. Archives of Microbiology 118, 13-20.

DE VRIES, G. E. (1986). Molecular biology of bacterial methanol oxidation. FEMS Microbiology Reviews 39, 235-258.

DE VRIES, G. E., Kues, U. \& Staht, U. (1990). Physiology and genetics of methylotrophic bacteria. FEMS Microbiology Reviews 75, 57-102.

Weber, K. \& Osborn, M. (1975). Proteins and sodium dodecyl sulphate: molecular weight determination on polyacrylamide gels and related procedures. In The Proteins 3rd edn, vol. 1, pp. 179-223. Edited by H. Neurath \& R. L. Hill. London: Academic Press.

Wood, P. M. (1984). Bacterial proteins with CO-binding $b$ - or $c$-type haem. Functions and absorption spectroscopy. Biochimica et Biophysica Acta 768, 293-317. 